\title{
AN OVERVIEW OF THE INTERGENERATIONAL FINANCIAL TRANSFERS IN ROMANIA
}

https://doi.org/10.47743/jopafl-2021-21-08

\author{
Alexandra Cristina SIRBU \\ Alexandru Ioan Cuza University of Iaşi, Faculty of Economics and Business \\ Administration \\ Iaşi, Romania \\ sirbuac@gmail.com \\ Adelina PANAITE \\ Alexandru Ioan Cuza University of Iaşi, Faculty of Economics and Business \\ Administration \\ Iaşi, Romania \\ adelina.panaite97@gmail.com \\ Mircea ASANDULUI \\ Alexandru Ioan Cuza University of Iaşi, Faculty of Economics and Business \\ Administration \\ Iaşi, Romania \\ mircea.asandului@uaic.ro
}

\begin{abstract}
Intergenerational transfers are one of the most important and contentious aspects of modern welfare systems. In today's societies, financial transfers between adult generations in the family are an important part of the intergenerational link. They are important not only for the family as a whole - how it distributes its resources and ensures its members' well-being - but also for broader aspects such as welfare policy, social inequality, and social integration. The financial transfers are playing an important role in accumulation and distribution of the wealth. In consequence these financial transfers are important not only for the individuals, but also for the social aspects of the wealth redistribution. Using the dataset provided by Survey of Health, Ageing and Retirement in Europe (SHARE), we want to create the profile of the persons over 50 from Romania that give and receive financial aid.
\end{abstract}

Keywords: Intergenerational transfers, financial transfers, private transfers, SHARE.

This Article was presented as a paper at the $13^{\text {th }}$ edition of the Annual International Conference Globalization and Higher Education in Economics and Business Administration (GEBA 2021), which was held at the Alexandru Ioan Cuza University, Faculty of Economics and Business Administration in Iasi, Romania from the $21^{\text {st }}$ to $23^{\text {rd }}$ of October 2021. 


\section{Introduction}

During the periods when changes in the structure of the family, in the attitude towards the family and in the values about familism exist, there is a growing interest in intergenerational solidarity. This interest is even stronger in the wake of structural problems, such as rising unemployment, rising costs and services, and an aging population. During these periods there is a tendency for the state to transfer the social responsibilities to the private sector, most often represented by the family (Bawin-Legros and Stassen, 2002). Financial transfers and assistance with daily activities by family and friends are important sources of support that contribute to the well-being of the elderly. The transfer of resources to the elderly is critical for both the family and society, with economic resources possibly being the most important (Leeson and Khan, 2013; Arber, 2013). Europe is an aging continent, and the need for long-term care will almost certainly increase in the coming decades. Children have always been an important source of care for parents in their old age. Furthermore, as the population ages, there is a growing concern for the elderly's well-being. If transfers between children and parents are significant, one might believe they should be considered when assessing population welfare. Most studies on intergenerational financial support focus on the reasons for thus exchanges. Given the lack of literature on intergenerational transfers made and given by Romanian older adults, in this paper we aim to provide an overview of financial transfers given and received by people over 50. We explore who gives and who receives financial support, as well as the profile of donors and recipients.

The paper is structured as follows: Section 1 summarizes the relevant literature, including both theoretical and empirical studies; Section 2 describes the methodology used in our study; Section 3 discusses the empirical findings and Section 4 will contain the conclusions of the study.

\section{Literature review}

Financial transfers are important not only for individuals, but also for social policies involving wealth redistribution. The direction in which they flow - upwards to the elderly population or downwards to younger families with children - has been reshaped by the establishment of welfare systems: older people who were previously economically supported by their children have since become providers of financial support to their offspring (Attias-Donfut, 1995; Kohli, 1999). Moreover, the literature presents that repayment of perceived debts and altruistic kinship commitments have been proposed as two key normative incentives for adult children to provide late-life financial support to parents (Cao, 2006; Hayhoe and Stevenson, 2007; Koh and MacDonald, 2006). Reciprocity norms are societal beliefs about adult children's obligations to repay their parents for earlier sacrifices made on their behalf (Silverstein et al., 2002). Financial assistance is intended to be provided as parents age in exchange for the services and financial support provided to their children as children and even into adulthood.

The motivations for intergenerational transfers can differ depending on the type of intergenerational transfer. Economic research on the motivation for intergenerational transfers has frequently relied on two models: altruistic and exchange models. That is, intergenerational transfers, particularly monetary assistance between generations, are the 
result of altruistic preference for family members (Becker, 1974; 1991) or mutual perceived advantage in transacting or engaging in joint production by family members (Becker, 1974). They reflect social ties between generations while also influencing those relationships. Adult children who receive financial assistance from older generations benefit economically, but their parents benefit as well because these gifts strengthen their children's affectionate bonds with them (Aquilino, 1991). This may be important later in life because feelings of closeness and solidarity have been linked to important outcomes for aging individuals, including aspects of mental and physical health. Also, the literature largely acknowledges the altruism towards family members in homeland as the main reason for remitting. Migration and remittances, without a doubt, relieve the sending countries of underemployment and create new opportunities, as well as help alleviate poverty and improve life in poor countries (Adams and Page, 2005; Spatafora, 2005; Gupta and al., 2009). Remittances have the strongest economic impact on sending countries, as the money sent home by migrant workers plays an important role for both receiving households and the economy (Gubert, 2002; Ratha, 2004; Gammage, 2006; Skeldon, 2007).

Prior research also focused on different types of transfers separately. According to Attias-Donfut et al. (2005), the likelihood of making family intergenerational financial transfers decreases with age, whereas the likelihood of receiving practical support significantly increases, particularly after the age of 75. Regardless of age, Albertini et al. (2007) discovered that parents are more likely to give financial support to their children than to receive it from them. Parents aged 70 and older, on the other hand, were more likely to receive than to provide practical support, excluding grandchild care. Researchers also investigated the geographical distribution of family transfers. They discovered that financial family transfers are the least common and most intensive in Southern Europe, while they are the most common and least intensive in Northern Europe (e.g., Albertini and Kohli, 2012; Kohli and Albertini, 2007). A similar geographic pattern was discovered for the exchange of non-monetary family help and care (Brandt and Deindl, 2013; Brandt et al., 2009; Deindl and Brandt, 2011; Haberkern and Szydlik 2010; Igel and Szydlik, 2011). The reasons for generational solidarity vary, but the literature emphasizes altruism among family members, particularly among parents toward their children (Becker, 1991), as well as expectations of reciprocity between generations (Coleman, 1990), affection, and need (Fingerman et al., 2009; Fingerman et al., 2011).

\section{Data and methodology}

In this paper we use the dataset provided by Survey of Health, Ageing and Retirement in Europe (SHARE), which is the largest pan-European social science panel study that provides insights into the public health and socio-economic conditions of European citizens aged 50+. We use data from the Wave 8 of SHARE that was applied in 2020 and comprises 28 European countries (plus Israel). The sample of analysis proposed is composed of those respondents who provided or received a financial transfer and who are from Romania. Financial transfers were measured over a period of 12 months prior to the interview. According to the SHARE definition, financial transfers include received or provided financial or material gifts valued at least $€ 250$ (or local equivalents in local currency). Respondents were asked: "Now please think about the last twelve months. Not 
counting any shared housing or shared food, have you or your husband/ wife/ partner given any financial or material gift or support to any person inside or outside this household amounting to 250 euros or more?". In this context, the term "financial or material gift" is meant to describe "giving money" or to provide specific types of benefits such as health care, insurance, schooling, and home purchase down payment. Loans were not considered as being gifts. For financial transfers received, the same format was used. In the case of positive replies, respondents are put into a question loop that allows them to give details on up to three transfers. They were also asked to whom they gave or from who they received most frequently financial transfer during the past 12 months.

This paper aims to improve our knowledge and, at the same time, to give us a picture of the financial transfers granted and received by people over 50 in Romania. We explore who gives and who receives financial aid, as well as the profile of donors and recipients. The analysis proceeds in several stages. First, we will offer a picture of the financial transfers for each country to see where Romania stands in the European context. Next, we find out who is sending and receiving financial transfers in Romania. Subsequently we will test if there are differences between the income of those who provide a financial transfer and those who receive. Finally, using multiple correspondence analysis we will identify the profile of donors and receivers from the perspective of the main socioeconomic and demographic characteristics. Multiple correspondence analysis (MCA) is one of the methods used to analyze multivariate data that analyses cross-frequency tables (contingency tables) to explore the simultaneous relationships among variables (Benzécri, 1979, Burr \& Phillips, 1984). This exploratory technique uses maps to determine structures subjacent to the variable set. After obtaining this, it is possible to visually observe the distance between the categories of the qualitative variables and between the observations. Multiple correspondence analysis was chosen because it allows analyzing all outcomes simultaneously, characterizing the profiles of respondents who gave or received a financial transfer.

\section{Results}

Table 1 shows the pattern of financial transfers in the European countries. One of our interests is to see Romania's place in the European context. Concerning financial transfers made, only $16.04 \%$ of Romanian respondents reported having given 250 euros or more within the last 12 months to their family or other members of their social network. Romania ranks in the bottom 5 with Slovakia, Spain, Bulgaria, Latvia. As far as receiving financial transfers is concerned, overall rates are slightly lower than for giving transfers, Romania being in the top 10 countries, with an 8.77 percent. We observe that, in Romania and in other European countries, there is a tendency that older people are more likely to offer than receive financial transfers. Even though these transfers appear small at first sight, we must say that the threshold of 250 euros excluded multiple transfers of smaller amounts while capturing simultaneously the larger transfers.

The identities of the donors and beneficiaries of the transfers are shown in Figure 3. As we mentioned above, if the respondents gave a positive reply, they were put into a question loop that allows them to give details of up to three transfers. As far as the beneficiaries of financial transfers are concerned, in all three times when a transfer was offered, two main patterns can be discerned. Firstly, the recipients of these transfers are 
almost exclusively family members, and secondly, the path of financial transfers is overwhelmingly towards children. For all three transfers granted, children account for more than $60 \%$, followed by transfers to grandchildren for which $23.88 \%$ for the first transfer, $14.77 \%$ for the second and $4.17 \%$ for the third.

\section{Figure 1. Distribution of countries by} financial transfers granted

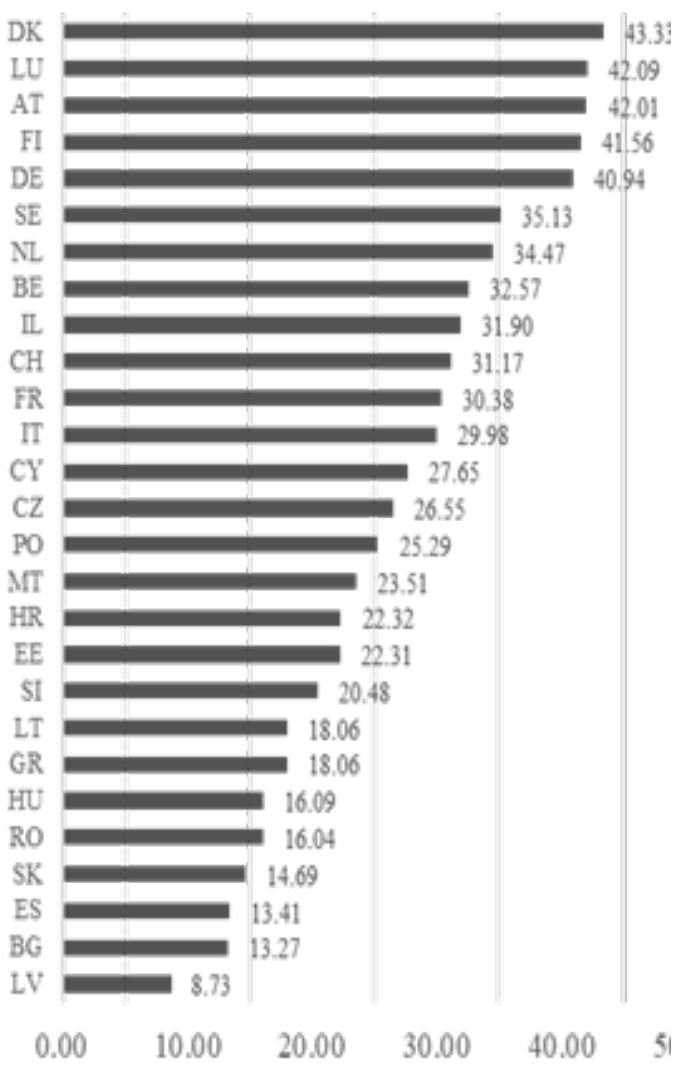

Figure 2. Distribution of countries by financial transfers received

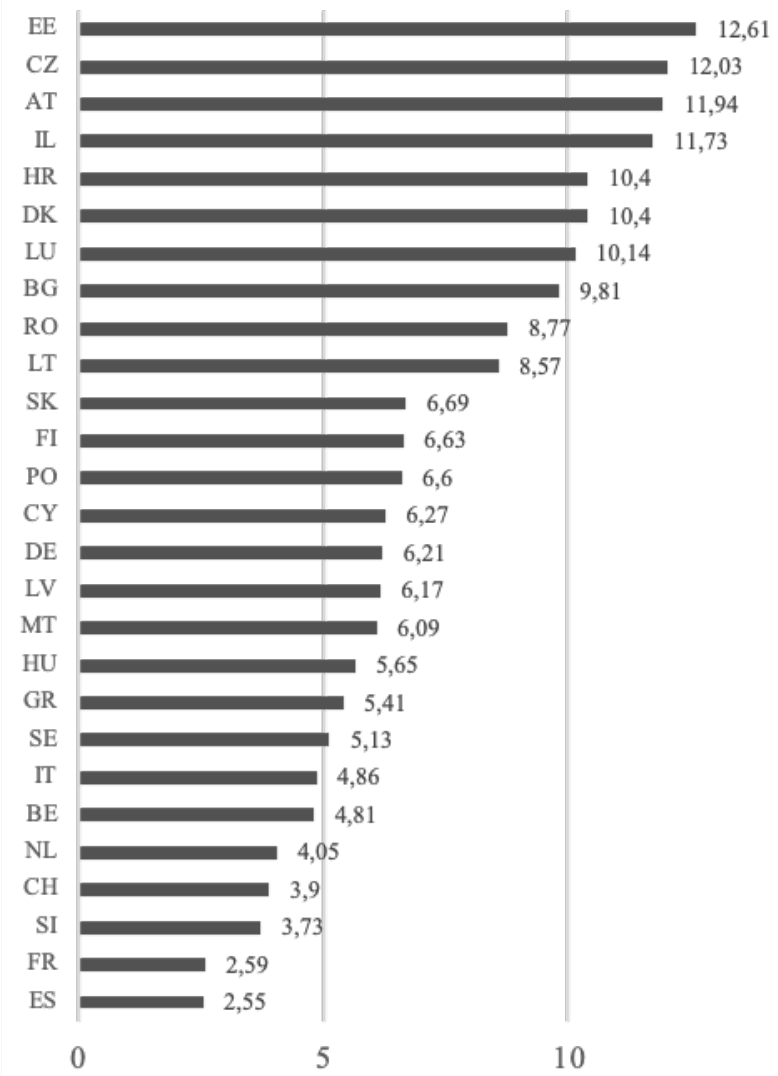

Source: SHARE 2020 (Release 1). Own calculations, weighted

Figure 3 presents the network of donors, those people from whom the respondent has received financial transfers. As for donors, children have the highest percentages, i.e., over $80 \%$ in all three cases of transfers received. It can also be noted that other family members form a small but important part of the network of transfers for the first and second received financial gift, while for the third transfer received, it is the non-family members who form an important part of the network. 
Figure 3: Financial transfer recipients and donors

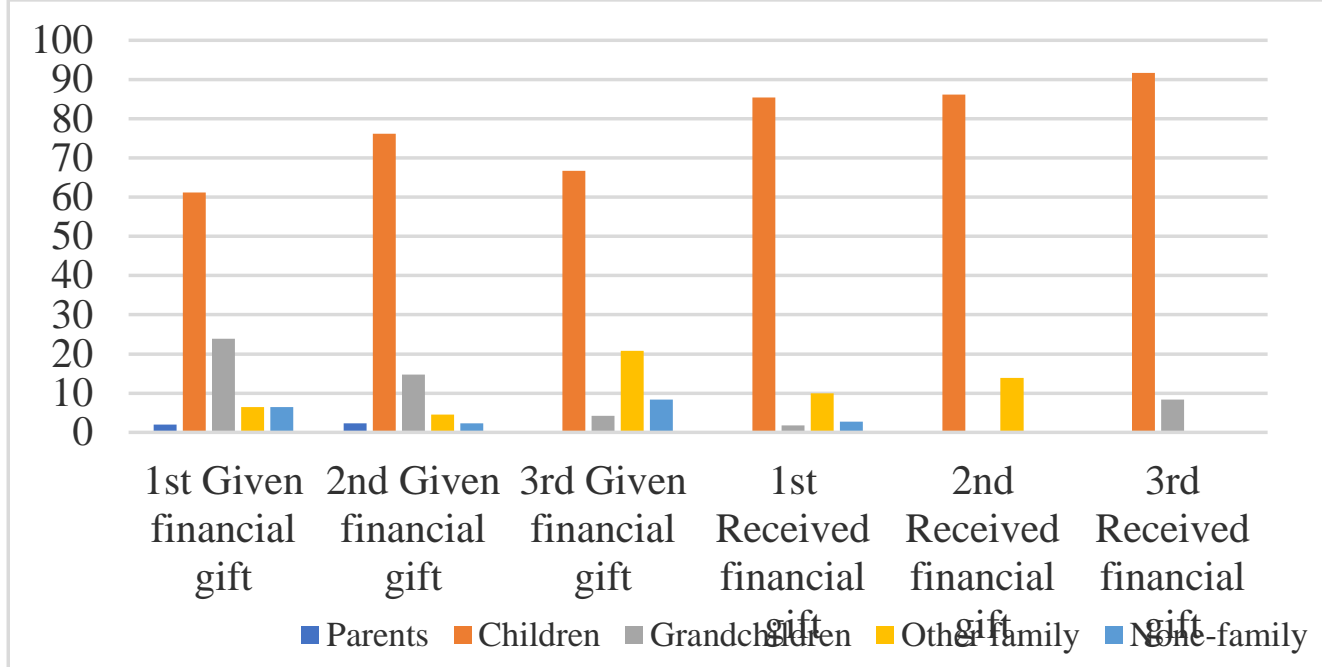

*Source: SHARE 2020 (Release 1). Own calculations, weighted.

Our results show that the process of financial transfers is concentrated especially in the family line, that cash gifts mainly flow to the younger generations. Having a downward flow, resource transfers from parents to children are much more frequent than those from children to parents. The results suggest that this type of support from the family is important in determining the accumulation of capital for younger generations (Ermisch, 2003; Altonji et al., 2012), acting as an insurance against income shocks while creating cohesion and solidarity among family members (Altonji et al., 1997, Chen et al., 2016).

Considering financial transfers, the economic circumstances of the recipient and giver are important. According to the literature, the better off a family is, the more likely they are to provide financial assistance and the greater the amount of aid will be with each transfer (Henretta et al., 2002; Albertini et al., 2007; Leopold \& Raab, 2011; Brandt \& Deindl, 2013). The study by Albuquerque (2014) observes that children may receive a financial transfer if their parents' financial situation is good, but that financial circumstances are not a predictor of child to parent transfers. Therefore, we want to investigate whether there are significant differences of income between the two categories of respondents, i.e. recipients and donors. Using the the simple Student test, we determine whether the mean income for donors is significantly different from the mean income for recipients. The results can be seen in Table 1.

Table 1. Independent samples Student test results

\begin{tabular}{|l|l|l|l|l|l|l|}
\hline Variable & Mean & $\begin{array}{l}\text { Standard } \\
\text { Error }\end{array}$ & $\begin{array}{l}\text { Standard } \\
\text { Deviation }\end{array}$ & 95\% Conf. Int. & $\begin{array}{l}\text { No. of } \\
\text { observat } \\
\text { ions }\end{array}$ \\
\hline Income of the donors & 728.7118 & 50.4322 & 714.9999 & 629.2647 & 828.1589 & 201 \\
\hline Income of the receivers & 577.6522 & 65.48198 & 686.7808 & 447.869 & 707.4353 & 110 \\
\hline Combined & 675.2824 & 40.13242 & 707.743 & 596.316 & 754.2488 & 311 \\
\hline $\begin{array}{l}\text { Diff = mean (Income of } \\
\text { the donors) - mean } \\
\text { (income of the receivers) }\end{array}$ & $\begin{array}{l}\mathrm{H}_{0}: \\
\mathrm{diff}=0\end{array}$ & $\mathrm{t}=1.8062$ & & -13.50439 & 315.6237 & $\begin{array}{l}\text { Degrees } \\
\text { of } \\
\text { freedom } \\
=309\end{array}$ \\
\hline
\end{tabular}




\begin{tabular}{|l|l|l|}
\hline $\mathrm{H}_{\mathrm{a}}:$ diff $<0$ & $\mathrm{H}_{\mathrm{a}}:$ diff $\neq 0$ & $\mathrm{H}_{\mathrm{a}}$ diff $>0$ \\
\hline $\operatorname{Pr}(\mathrm{T}<\mathrm{t})=0.9641$ & $\operatorname{Pr}(\mathrm{T}<\mathrm{t})=0.0719$ & $\operatorname{Pr}(\mathrm{T}<\mathrm{t})=0.0359$ \\
\hline *Source: Authors' calculations & \multicolumn{2}{|l|}{} \\
\hline
\end{tabular}

As we can notice, the test registers a value of 1.8062 with 309 degrees of freedom and a probability of 0.0719 ( $\mathrm{p}>0.05)$; this indicates that there are no significant differences between average incomes of donors and receivers.

Since there are no significant differences between donors and receivers in terms of income, it should be noted that the level of income is not the main reason for such transfers. We might say, in the present context, that these transfers are made as part of a reciprocal and symbolic exchange model with close relatives who are emotionally linked to each other. Future research will examine the reasons behind financial transfers among older adults to determine if they are driven by human capital and economic investment.

A final step in the current analysis is to build a profile of both the recipients and donors of financial transfers by meeting their most important characteristics using multiple correspondence analysis. We will assess the profile of donors and recipients in terms of age, gender, education level, residence area, marriage status and health status.

According to the MCA analysis, a two-dimensional solution was found to be most appropriate, as the first 2 factor axis explain the largest differences between those who were donors and those who weren't.

Figure 4. Representation of statistical variables in the system of the first two factor axis.

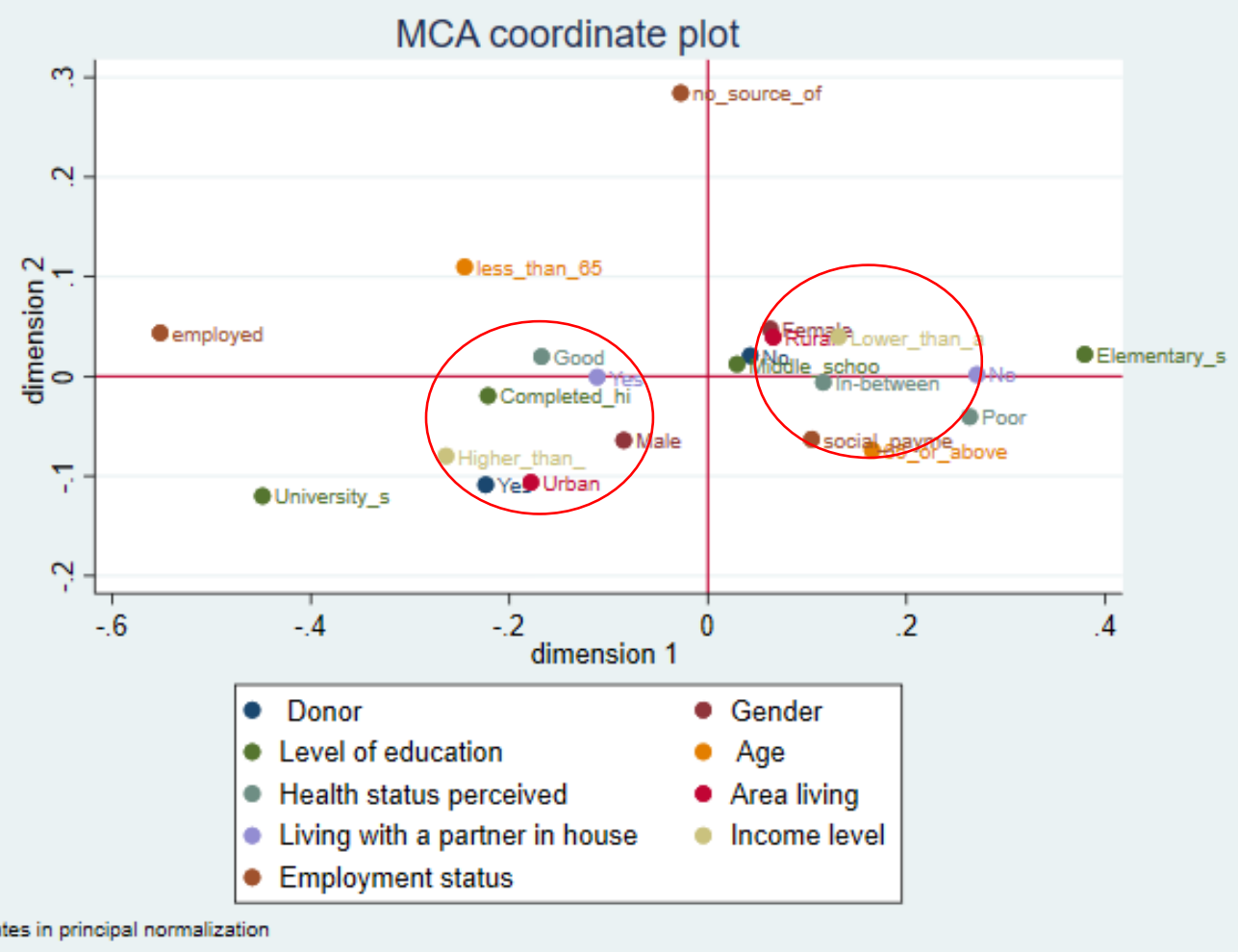

*Source: Authors' calculations 
According to Figure 4, the people who have granted a financial transfer live in urban areas, are men, have graduated high school, reside with a partner in the house, are in good health and have an income higher than average. All these details point to a high probability that a person is likely to grant a financial transfer. At the other end of the spectrum, those who have not been granted a financial transfer are those inbetween states of health, who live in rural areas, are women, have below-high school education, are over 65 years old, receive social assistance and have income lower than average. From their profile, we can conclude that people who are defined by the characteristics analysed are more likely to be unable to provide a financial transfer.

Regarding the profile of beneficiaries (Figure 5), we observe that they are healthy and educated up to a high school level, live in urban areas, have partners with whom they live together and have an income level above the national average. In light of this, we cannot characterize the recipients of financial transfers as being in a state of need and explain the financial transfers to them from the perspective of their need for assistance. The same cannot be said of individuals who haven't received a financial transfer in the last year and whose profile indicates the need for assistance.

Figure 5. Representation of statistical variables in the system of the first two factor axis

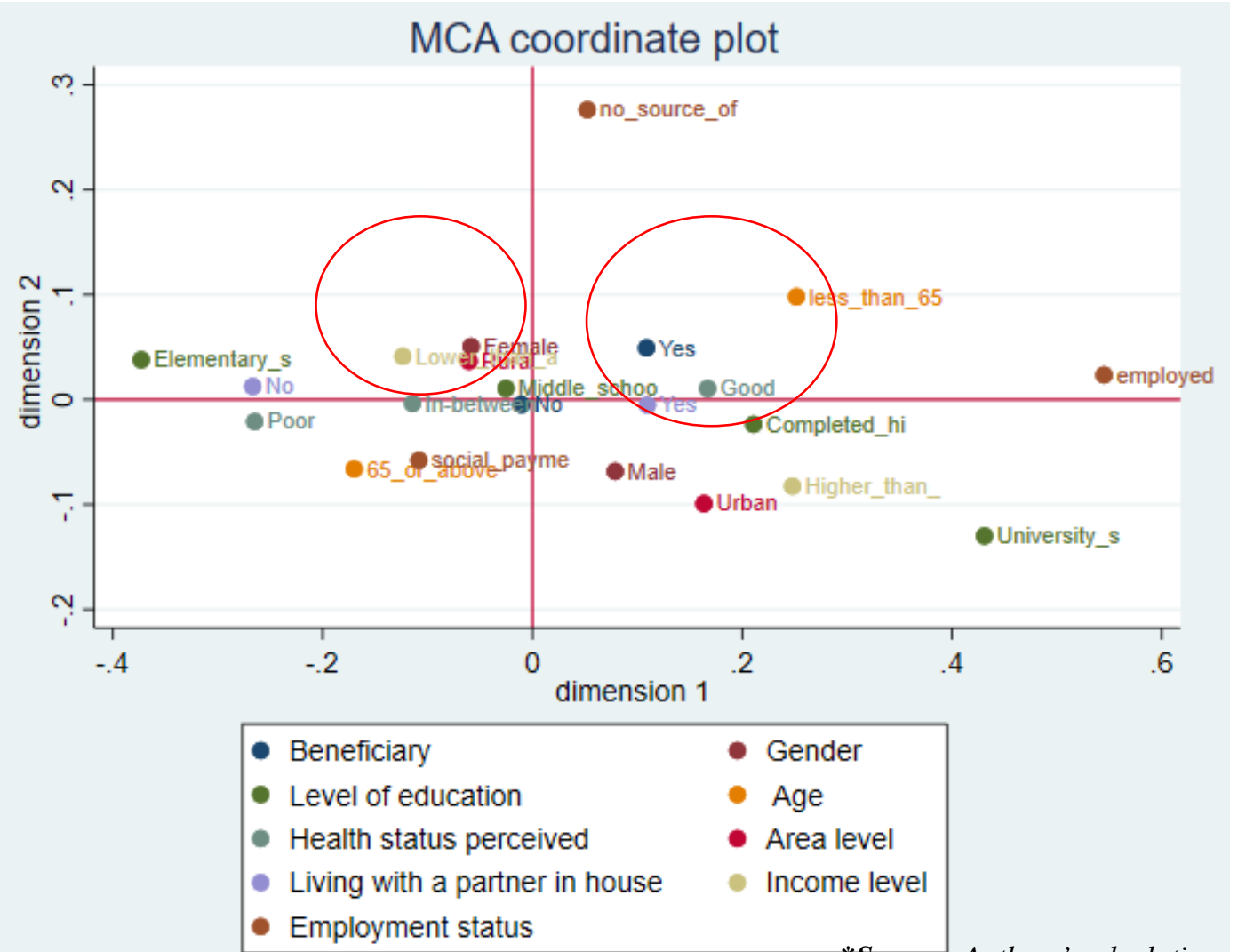


We can conclude that the financial transfers received by older adults in Romania are not based on low living standards, so that they are helping to increase their welfare. Apparently the transfers are generated by people who have good financial positions, which are also observed in the recipients of these transfers, confirming that the granting and receiving of transfers involving the sum of 250 euros or more are directed to close relatives in a mutual and symbolic exchange.

\section{Conclusions}

Our findings indicate that, in Romania, the incidence of financial transfers having the amount of 250 euro or more is relatively high, considering the number of the transfers. In addition, we found that transfers are clearly downward, with transfers from parents to children being much more frequent and also much more intense than transfers in the opposite direction. The reason for this might be the fact that both Romania and the rest of Europe have at least a minimum pension system in place, which allows older people to remain financially independent, enabling them to pass some of their assets on to their children and grandchildren.

A second aspect that was identified was that there are no significant differences in income between donors and recipients, excluding the possibility that those with a better financial situation would donate more money. Using multidimensional correspondence analysis, profiles of donors and recipients in terms of socio-demographic characteristics can be made. The results show that both donors and recipients have similar characteristics, which led to the conclusion that financial transfers of 250 euro or more were made in a reciprocal exchange model.

These initial exploratory and graphical results pave the way for further research into the determinants of intentions to make financial transfers. The study also emphasizes the MCA's strengths as a method that can visualize association between categorical and ordinal variables in a more intuitive manner.

\section{Acknowledgements}

The authors acknowledge financial support from the Romanian National Authority for Scientific Research and Innovation, CNCS -UEFISCDI - Project PN-IIIP4-ID-PCE- 2020-0929 Household Saving Behavior - A Socio-Economic Investigation from Households, Banks and Regulators Perspective.

\section{References}

1. Adams Jr, R. H., \& Page, J. (2005). Do international migration and remittances reduce poverty in developing countries?. World $\quad$ development, $\quad 33(10), \quad$ 1645-1669. https://doi.org/10.1016/j.worlddev.2005.05.004

2. Albertini, M., Kohli, M., \& Vogel, C. (2007). Intergenerational transfers of time and money in european families: common patterns_-different regimes? Journal of European Social Policy, 17(4), 319334. https://doi.org/10.1177/0958928707081068 
3. Albuquerque, P. C. (2014). Intergenerational private transfers: Portugal in the European context. European Journal of Ageing, 11(4), 301-312. https://doi.org/10.1007/s10433-014-0324-x

4. Altonji, J. G., Blom, E., \& Meghir, C. (2012). Heterogeneity in human capital investments: high school curriculum, college major, and careers. Annual Review of Economics, 4(1), 185-223. https://doi.org/10.1146/annurev-economics-080511-110908

5. $\quad$ Altonji, J. G., Hayashi, F., \& Kotlikoff, L. J. (1997). Parental altruism and inter vivos transfers: theory and evidence. Journal of Political Economy, 105(6), 1121-1166.

6. Aquilino W.S. (1991). Parent-child relations and parent's satisfaction with living arrangements when adult children live at home, Journal of Marriage and the Family, 53(1), 13-27 https://doi.org/10.2307/353130

7. Attias-Donfut, C., Ogg, J. and Wolff, F. C. (2005). European patterns of intergenerational financial and time transfers. European journal of Ageing, 2(3), pp. 161-173. https://doi.org/10.1007/s10433-005-0008-

$\underline{7}$

8. $\quad$ Attias-Donfut, C. (1995). Les solidarites entre generations, Nathan, Paris

9. Bawin-Legros, B. and Stassen, J. F. (2002). Intergenerational solidarity: between the family and the state. Current Sociology, 50(2), pp. 243-262 https://doi.org/10.1177/0011392102050002620

10. Becker, G. S. (1974). A Theory of Social Interactions, Journal of Political Economy, 82, 6, 10631093

11. Benzécri JP. Sur le calcul des taux d'inertie dans l'analyse d'un questionnaire, addendum et erratum à [BIN. MULT.]. Cahiers de l'Analyse des Données.1979,4,377-8.

12. Brandt, M., \& Deindl, C. (2013). Intergenerational transfers to adult children in Europe: Do social policies matter?. Journal of Marriage and Family, 75(1), 235-251. https://doi.org/10.1111/j.17413737.2012.01028.x

13. Burr ML, Phillips MK. Anthropometric norms in the elderly. Br J Nutr. 1984;51:165-9

14. Chen, T., Leeson, G. W., \& Liu, C. (2016). Living arrangements and intergenerational monetary transfers of older Chinese. Ageing and Society, 24(01), 1-26. https://doi.org/10.1017/S0144686X16000623

15. Deindl C., Brandt M. (2013). Intergenerational Transfers to Adult Children in Europe: Do Social Policies Matter?, Journal of Marriage and Family, 75(1) https://doi.org/10.1111/j.17413737.2012.01028.x

16. Ermisch, J. (2003). An Economic Analysis of the Family. USA: Princeton University Press.

17. Fingerman K.L. (2011). Who Gets What and Why? Help Middle-Aged Adults Provide to Parents and Grown Children, The Journals of Gerontology: Series B, Volume 66B https://doi.org/10.1093/geronb/gbq009

18. Henretta, J. C., Hill, M. S., Li, W., Soldo, B. J., \& Wolf, D. A. (1997). Selection of children to provide care: the effect of earlier parental transfers. The Journals of Gerontology Series B: Psychological Sciences and Social Sciences, 52B(Special), 110-119.

19. R. A. Johnson and D. W. Wichern, Applied Multivariate Correspondence Analysis, Prentice-Hall, Upper Saddle River, NJ, USA, 6th edition, 2007

20. Leeson, G.W., Khan H.T. (2013). Factors Associated with Intergenerational Social Support among Older Adults across the World, Springer

21. Leopold, T., \& Raab, Ml. (2011). Short-term reciprocity in late parent-child relationships. Journal of Marriage and Family, 73(1), 105-119. https://doi.org/10.1111/j.1741-3737.2010.00792.x

22. MacDonald, M., Koh, S.K. (2006). Consistent Motives for Inter-Family Transfers: Simple Altruism, Journal of Family and Economics Issues, 27, 73-97 https://doi.org/10.1023/A:1022435104422

23. Silverstein M., Conroy J., Haitao W., Roseann G., Vern L. B. (2002). Reciprocity in Parent-Child Relations Over the Adult Life Course, Series (b), Oxford Academic

24. Skeldon R. (2007). Quantifying international migration: A database of bilateral migrant stocks, World Bank Policy Research Working Paper

\section{๑๑ఠ}

BY No ND This article is an open access article distributed under the terms and conditions of the Creative Commons Attribution - Non Commercial - No Derivatives 4.0 International License. 